\title{
The validity of the Bayley-Pinneau method in predicting final adult height at the onset of puberty in patients with classic congenital adrenal hyperplasia
}

\author{
Nora Badawi', Lubna Fawaz', Ahmed Amin ${ }^{\circledR 1}$, Abdelkarim Kamel' ${ }^{2}$, Noha Arafa (1)1 \\ ${ }^{1}$ Department of Paediatrics, Faculty of Medicine, Cairo University, Cairo, Egypt \\ ${ }^{2}$ Department of Medical Biochemistry, Faculty of Medicine, Cairo University, Cairo, Egypt
}

\begin{abstract}
Introduction: The final adult height $(\mathrm{FAH})$ of patients with congenital adrenal hyperplasia (CAH) is often lower than the predicted adult height (PAH) using the Bayley-Pinneau (B\&P) method. The aim of the current work was to test the validity of B\&P in predicting FAH from a bone age (BA) measurement performed at onset of puberty.

Material and methods: This was a retrospective longitudinal observational convenience single-centre study. The study included 54 patients (male and female) with classic $\mathrm{CAH}$, whether salt-wasting (SW) or simple virilising (SV), who had reached FAH. The results of auxological measurements and hormonal data around the time of puberty were retrieved from files. Predicted adult height (PAH) was calculated from a BA taken at onset of puberty and compared with FAH.

Results: The median PAH SDS at the onset of puberty $(-1.5)$ was significantly greater than the median FAH SDS $(-2.2)(p<0.001)$. The median target height SDS $(-0.8)$ was significantly higher than the median FAH SDS $(-2.2)(\mathrm{p}<0.001)$. FAH and FAH SDS were significantly worse in females $(150.36 \pm 7.23 ;-2.05 \pm 1.13)$ than in their male counterparts $(162.86 \pm 3.30 ;-1.53 \pm 0.51)$ ( $p$ value $<0.001 ; 0.048)$. In patients with good control, there was no difference between PAH SDS $(-1.7)$ and FAH SDS $(-1.5)$ ( $\mathrm{p}$ value $=0.37)$. In patients with poor control (over- or under-treated) FAH SDS $(-2.1)$ was significantly lower than PAH SDS $(-1.4)$ (p value $<0.001)$.

Conclusion: The B\&P method was able to accurately predict FAH in children with classic CAH, who were medically well controlled (based on 17-hydroxyprogesterone levels), but overestimated it by a significant $0.7 \mathrm{SD}$ in poorly-controlled patients. (Endokrynol Pol 2021; 72 (4): 301-307)
\end{abstract}

Key words: classic congenital adrenal hyperplasia; Bayley-Pinneau method; predicted adult height; final adult height; bone age

\section{Introduction}

Congenital adrenal hyperplasia $(\mathrm{CAH})$ is a spectrum of inherited autosomal recessive mutations affecting the enzymatic steps required for adrenal steroid synthesis [1]. The global prevalence of classic $\mathrm{CAH}$ is $1: 15,000$ people [2]. However, a higher prevalence (1:1209) was reported among Egyptian newborns based on the biochemical analysis of 17-hydroxy progesterone levels (17OHP) [3]. Clinically, CAH is classified into different phenotypes: classic [including salt-wasting (SW) and simple virilizing (SV) forms] and non-classic (NC). In SW CAH, crises in the form of hypovolaemia, hyponatraemia, and hyperkalaemia start early in the neonatal period associated with ambiguous genitalia in females and elevated adrenal precursors (17OHP, delta-4 androstenedione, and testosterone). SV CAH presents with precocious puberty in boys and a variable degree of virilization in girls in the presence of elevated $17 \mathrm{OHP}$ with no clinical or biochemical evidence of SW crisis [4].
The cornerstone treatment is glucocorticoid replacement, preferably at a hydrocortisone level of $10-15 \mathrm{mg} / \mathrm{m}^{2} /$ day [5]. Lifetime monitoring and regular dose adjustment of glucocorticoids and mineralocorticoids are crucial in the management of $\mathrm{CAH}$ patients, to optimize growth and pubertal development [6]. Insufficient steroid therapy results in inadequate suppression of excessive androgen secretion, which leads to abnormal accelerated skeletal maturation with subsequent early epiphyseal fusion and suboptimal final adult height (FAH). Conversely, excessive steroid dose can directly suppress growth via a direct effect on growing growth plates. The main challenge in the management of patients with $\mathrm{CAH}$ is to minimize the fluctuations between hyperandrogenaemia and hypercortisolism, which occur due to the short half-life (one hour) of hydrocortisone [1,7]. Previous observational studies and meta-analyses have reported reduced FAH in CAH patients compared to normal populations, as well as their parental genetic potentials [6]. Height prediction based 
on bone age using the Bayley-Pinneau (B\&P) method seeks to determine the potential for growth and may help with crucial clinical decisions [8].

Our goal in this study was to test the validity of the B\&P method in predicting FAH at the onset of puberty in children with classic $\mathrm{CAH}$ (SW or SV). We also aimed to identify factors that influence FAH.

\section{Material and methods}

This was a retrospective longitudinal observational single-centre study conducted in the Diabetes Endocrine and Metabolism Paediatric Unit (DEMPU), The Children's Hospital, Cairo University on a convenience sample of patients.

\section{Inclusion criteria}

All patients, male or female, with classic CAH due to 21-hydroxylase deficiency, whether SW or SV, who had been regularly followed up in our clinic since diagnosis, had achieved FAH, and had undergone an X-ray of the left hand and wrist at the onset of puberty for bone age (BA), were eligible for evaluation. The onset of puberty was defined by a testicular size of $4 \mathrm{~mL}$ (T2) in male children and a breast size of B2 in females [9]. FAH was defined as a growth velocity < $1 \mathrm{~cm}$ in the previous year and/or a bone age $>15$ years in females or $>16$ years in males or height recorded after the age of 20 years in males or 18 years in females [10].

\section{Exclusion criteria}

Patients with skeletal or other chronic growth-altering disorders or those who received growth hormone were excluded.

Data at diagnosis and height at the onset of puberty were retrieved from patients' files. Because genetic diagnosis was not available, the diagnosis of classic $\mathrm{CAH}$ was based on clinical and biochemical data (done after organic extraction) and patients were divided into SW or SV for comparison: a) salt-wasting form (SW) - salt-wasting crisis started early in the neonatal period in the form of hypovolaemia, hyponatraemia, or hyperkalaemia, associated with ambiguous genitalia in females with confirmatory elevated adrenal precursors (17-hydroxy progesterone-androstenedione-testosterone); b) simple virilising form (SV) - precocious puberty in boys and variable degree of virilization in girls in the presence of elevated 17-hydroxy progesterone (17OHP) with no clinical or biochemical evidence suggestive of SW crisis.

History included the following: age at diagnosis, age at time of study, onset of puberty and menarche in females, and detailed therapy at the time of puberty - hydrocortisone dose, fludrocortisone dose, and luteinising hormone-releasing hormone analogues (LHRHa) to delay puberty. Results of hormonal analyses from samples taken at 8 a.m. at the time of $B A$ were retrieved from patient files (17OHP, testosterone, delta-4-androstenedione). Adequate steroid replacement at time of puberty was defined by a $17 \mathrm{OHP}$ level of 5-7 ng/mL [7] with lower levels considered as over-treatment [except in males with testicular adrenal rest tumours (TART) where lower levels are desirable to suppress ACTH levels [11], and higher levels as under-treatment].

Anthropometric measurements were performed according to International Biological Programme [12]. Body weight was measured using the Seca scale. The weight was recorded to the nearest $0.1 \mathrm{~kg}$. FAH was measured using a Harpenden stadiometer and recorded to the nearest $0.1 \mathrm{~cm}$. Body mass index (BMI) was calculated as weight $(\mathrm{kg}) /$ height $(\mathrm{m})^{2}$. Target height $(\mathrm{TH})$ was calculated from the data of parental measurements, as follows: maternal height + paternal height + or $-13 \mathrm{~cm}$ for males and females, respectively $/ 2$. Standard deviation scores for body weight, height, BMI, and target height $(\mathrm{TH})$ were calculated using a Growth Vision computer system software provided by Novonordisc.
BA was assessed at the onset of puberty from an X-ray of the left hand and wrist using the Greulich and Pyle method [13], and predicted adult height (PAH) was calculated by Bayley-Pinneau $(\mathrm{B} \& \mathrm{P})[14]$ prediction using the appropriate tables for girls and boys according to the relation of bone age to chronological age (CA) whether average (BA within one year of CA), retarded, or accelerated [13]. Gain in height was defined as FAH-PAH at the onset of puberty. Written informed consent was obtained from all participants. The study was approved by the Research Ethics Committee of Cairo University (IRB: I-091017) and conducted in accordance with the Helsinki Declaration.

\section{Statistical methods}

Descriptive analyses were presented as mean \pm standard deviation (SD) or median and interquartile range (IQR) for numerical variables or number and percentages for categorical variables. Comparison between numerical variables was performed using the Mann-Whitney U test. Comparison between categorical data was performed using the chi-square test or Fisher's exact test. Correlations were performed using Spearman correlation coefficient test. $P$ value $\leq 0.05$ was considered significant, and highly significant if $<0.01$. SPSS software (version 16 windows) was used for data analysis.

\section{Results}

\section{Demographic data}

Fifty-four patients with classic $\mathrm{CAH}$ were included. The female:male ratio was $40: 14$ (74.1\% vs. $25.9 \%)$. The median age in the study group was 20 years (IQR 20-28). Twenty-three patients (42.6\%) were diagnosed as SW CAH (18 females, 5 males), and 31 patients (57.4\%) were SV CAH (22 females, 9 males). Median age at diagnosis of patients with SW CAH was as early as 8 weeks (IQR: $4.5-16$, range: $0.14-17.1$ weeks), and it was 2.75 years (IQR: $0.75-4.5$, range: $0.09-11.65$ years) for SV CAH patients. All patients were treated entirely with hydrocortisone as glucocorticoid replacement therapy in three divided daily doses. The median dose of hydrocortisone among the whole studied group was $15 \mathrm{mg} / \mathrm{m}^{2} /$ day (IQR: 10.7-20). Fludrocortisone was used by 46 patients $(85.2 \%)$. Nine patients $(16.7 \%)$ received LHRH analogue to delay pubertal onset. Puberty was early in $38.7 \%$ of patients, normal in $21.3 \%$, and delayed in $40 \%$. Menarche was early in $12.5 \%$, occurred at a normal age in $3 \%$, and was delayed in $84.3 \%$. Two females had polycystic ovarian syndrome (PCOS), and three males had TART. The clinical characteristics and hormonal profile at the age of pubertal onset are shown in Table 1.

\section{Auxological data}

Auxological and BA data of the study group are presented in Table 2. Chronological age (CA) was delayed compared to BA at onset of puberty. Twenty-nine cases $(53.7 \%)$ had BA within one year of CA, 7 patients $(13 \%)$ had delayed BA, and 18 patients $(33.3 \%)$ had advanced BA. 
Table 1. Clinical characteristics and hormonal profile of the study group $(n=54)$

\begin{tabular}{lcccc}
\hline \multirow{2}{*}{ Parameters } & \multicolumn{2}{c}{ Females $(\mathbf{n}=\mathbf{4 0})$} & \multicolumn{2}{c}{ Males $(\mathbf{n}=\mathbf{1 4})$} \\
\cline { 2 - 5 } & Median & IQR & Median & IQR \\
\hline Age (years) & 23 & $20-28$ & 21.5 & $19.25-27.25$ \\
\hline Age of onset of puberty [yrs] & 12 & $10-13$ & 12 & NA \\
\hline Age at menarche $[\mathrm{yrs}]$ & 15 & $14-16.25$ & $\mathrm{NA}$ & NA \\
\hline Number of years between onset & 3 & $2-4$ & $\mathrm{NA}$ & $12.42-19.5$ \\
\hline of puberty and menarche & 15 & $10.35-20$ & 16 & $0.1-0.21$ \\
\hline Dose of hydrocortisone $\left[\mathrm{mg} / \mathrm{m}^{2} / \mathrm{day}\right]$ & 0.1 & $0.1-0.25$ & 0.1 & $1.17-9.35$ \\
\hline Dose of fludrocortisone $[\mathrm{mg} / \mathrm{day}]$ & 10.85 & $3.6-20$ & 4.4 & $2.27-12.2$ \\
\hline 17 OHP $[\mathrm{ng} / \mathrm{mL}]$ & 3.1 & $1.25-12.55$ & 9.9 & $0.25-1.5$ \\
\hline DHEA $[\mathrm{ng} / \mathrm{mL}]$ & 2.35 & $0.95-10$ & 0.8 & $0.41-2.07$ \\
\hline Delta 4 androstenedione $[\mathrm{ng} / \mathrm{mL}]$ & 0.7 & $0.29-1.77$ & 0.8 & \\
\hline Testosterone $[\mathrm{ng} / \mathrm{mL}]$ & & & & \\
\hline
\end{tabular}

170HP — 17-hydroxy progesterone; DHEA — dehydroepiandrosterone; IQR — interquartile range. All laboratory results reflect levels at the onset of puberty

Table 2. Auxological and bone age data in the study group $(n=54)$

\begin{tabular}{lcc}
\hline Parameters & Median & IOR \\
\hline Target height $[\mathrm{cm}]$ & 158.8 & $154.1-164.5$ \\
\hline Target height SDS $(\mathrm{n}=27)$ & -0.8 & -1.6 to 0.15 \\
\hline FAH [cm] & 153.50 & $147.15-159.85$ \\
\hline FAH SDS & -2.05 & -2.60 to -1.30 \\
\hline PAH [cm] & 156.80 & $151.65-161.90$ \\
\hline PAH SDS & -1.5 & -2.4 to -0.7 \\
\hline Final weight SDS & 0.75 & -0.4 to 2.30 \\
\hline Final BMI SDS & 1.6 & 0.70 to 2.50 \\
\hline BA at pubertal onset [yrs] & 12.0 & $11.0-14.0$ \\
\hline CA at time of BA [yrs] & 11.50 & $9.0-14.0$ \\
\hline BA-CA [yrs] & 1.0 & $0-2.0$ \\
\hline CA/BA [yrs] & 0.94 & $0.82-1.0$ \\
\hline Percentage of FAH at time of bone & 90.75 & $88.0-94.80$ \\
age (B\&P) & & \\
\hline
\end{tabular}

FAH — final adult height; $\mathrm{PAH}$ — predicted adult height; $\mathrm{BMI}$ — body mass index; $\mathrm{BA}$ — bone age; $\mathrm{CA}$ — chronological age; $\mathrm{CA} / \mathrm{BA}$ — chronological age/ bone age at start of puberty; B\&P — Bayley and Pinneau

Target height was available for 27 patients. The median target height SDS (-0.8) was significantly higher than the median FAH SDS $(-2.2)(\mathrm{p}<0.001)$. The median PAH SDS at the onset of puberty $(-1.5)$ was also significantly greater than the median FAH SDS $(-2.2)(\mathrm{p}<0.001)$. FAH and FAH SDS were significantly worse in females $(150.36 \pm 7.23 ;-2.05 \pm 1.13)$ than in their male counterparts $(162.86 \pm 3.30 ;-1.53 \pm 0.51)$ ( $\mathrm{p}$ value $<0.001 ; 0.048)$ (Tab. 3$)$.

Evaluation of FAH according to CAH type among the whole cohort revealed that there were no differences between SW and SV regarding CA/BA at time of puberty, FAH, or FAH/TH, (Tab. 4). However, males with SW CAH had significantly lower FAH SDS $(-2.5 \pm 0.44)$ than males with SV CAH $(-1.33 \pm 0.38)$ ( $p$ value 0.01 ). There was no difference between females with SW CAH and those with SV CAH regarding FAH SDS ( $p$ value 0.67 ) (Tab. 3). Additionally, male patients on lower hydrocortisone dose $\left(\mathrm{HC}<15 \mathrm{mg} / \mathrm{m}^{2} / \mathrm{d}\right)$ had significantly better FAH SDS $(-1.31 \pm 0.25)$ when compared to males on higher dose $(-1.84 \pm 0.59)$, with $\mathrm{p}$ value $=0.04$.

Concerning metabolic control guided by the level of 17OHP levels at puberty, $17(31.5 \%)$ patients had suppressed levels, 8 patients $(14.8 \%)$ had levels within the desired range, and 29 patients $(53.7 \%)$ had levels above the desired range. There was no difference in FAH between those with good control at the time of onset of puberty and those with poor control (median $=-1.5$, IQR: $-2.7,-1.35$ vs. -2.1 , IQR: $-2.6,-1.25)(p=0.06)$. In patients with good control, there was no difference between PAH and FAH SDS. Also, TH was available for $6 / 8$ patients with good control. TH was significantly higher than $\mathrm{PAH}$ in these patients $(-1.1 \pm 0.68 \mathrm{SD}$ vs. $-2.0 \pm 0.78$ $\mathrm{SD}, \mathrm{p}=0.03$ ). In patients with poor control (over- or under-treated) FAH was significantly lower than PAH. TH was available for 21/46 patients with poor control, and TH was significantly higher than PAH in these patients $(-0.8 \pm 1.07 \mathrm{SD}$ vs. $-1.41 \pm 1.09 \mathrm{SD}$, $\mathrm{p}=0.03$ ) (Tab. 5).

There was a negative correlation between final height SDS on the one hand and BA at onset of puberty $(\mathrm{r}=-0.29, \mathrm{p}=0.034)$, percentage of final height at time of BA ( $\mathrm{r}=-0.34, \mathrm{p}=0.02)$ and dose of fludrocortisone $(\mathrm{r}=-0.41, \mathrm{p}=0.005)$ on the other. There was a positive correlation between FAH SDS and weight $(r=0.32$, 
Table 3. Differences between males vs. females (SW vs. SV) (those on hydrocortisone dose $<15 \mathrm{mg} / \mathrm{m}^{2} / \mathrm{d}$ vs. those on $>15 \mathrm{mg} /$ $\left.\mathrm{m}^{2} / d\right)$ in each sex group $(n=54)$ with regard to mean final $(F A H)$ and predicted $(P A H)$ adult height and their SDS

\begin{tabular}{|c|c|c|c|c|c|}
\hline Parameters & \multicolumn{2}{|c|}{ Males $(n=14)$} & \multicolumn{2}{|c|}{ Females $(n=40)$} & \multirow{2}{*}{$\begin{array}{l}\text { p value } \\
<0.001\end{array}$} \\
\hline FAH [cm] & $162.86 \pm 3.30$ & & $150.36 \pm 7.23$ & & \\
\hline FAH SD & $-1.53 \pm 0.51$ & & $-2.05 \pm 1.13$ & & 0.048 \\
\hline PAH SD & $-0.5 \pm 0.50$ & & $-1.57 \pm 1.3$ & & 0.39 \\
\hline \multirow[t]{2}{*}{ FAH-PAH SD } & $-0.72 \pm 0.41$ & & $-0.50 \pm 0.96$ & & 0.62 \\
\hline & $S W(n=5)$ & $S V(n=9)$ & $S W(n=18)$ & $S V(n=22)$ & \\
\hline FAH SD & $-2.5 \pm 0.44$ & $-1.33 \pm 0.38$ & $-2.12 \pm 1.14$ & $-1.97 \pm 1.15$ & \\
\hline \multirow[t]{3}{*}{$\mathrm{p}$ value } & 0.01 & & 0.67 & & \\
\hline & $\begin{array}{c}\mathrm{HC}<15 \mathrm{mg} / \mathrm{m}^{2} / \mathrm{d} \\
(\mathrm{n}=7)\end{array}$ & $\begin{array}{c}\mathrm{HC}>15 \mathrm{mg} / \mathrm{m}^{2} / \mathrm{d} \\
(\mathrm{n}=7)\end{array}$ & $\begin{array}{c}H C<15 \mathrm{mg} / \mathrm{m}^{2} / \mathrm{d} \\
(\mathrm{n}=20)\end{array}$ & $\begin{array}{c}H C>15 \mathrm{mg} / \mathrm{m}^{2} / \mathrm{d} \\
(\mathrm{n}=20)\end{array}$ & \\
\hline & $-1.31 \pm 0.25$ & $-1.84 \pm 0.59$ & $-2.02 \pm 1.19$ & $-2.04 \pm 1.13$ & \\
\hline$p$ value & 0.04 & & 0.93 & & \\
\hline
\end{tabular}

HC — hydrocortisone; SD — standard deviation; SW — salt-wasting; SV — simple-virilising

Table 4. Comparison between salt wasters and simple virilisers congenital adrenal hyperplasia (CAH) patients regarding chronological age/bone age $(C A / B A)$ at time of puberty, final adult height $(F A H)$, and final adult height/target height $(F A H / T H)$

\begin{tabular}{lccc}
\hline $\begin{array}{l}\text { Mean } \pm \text { SD } \\
\text { (range) }\end{array}$ & Type of CAH & Salt wasters \\
& $(\mathbf{n}=\mathbf{2 3})$ & $\begin{array}{c}\text { Simple virilisers } \\
(\mathbf{n}=\mathbf{3 1})\end{array}$ & $\mathbf{p}$ value \\
CA/BA at time of puberty & $0.96 \pm 0.16$ & $0.93 \pm 0.17$ & 0.48 \\
& $(0.66-1.3)$ & $-1.78 \pm 1.03$ & 0.27 \\
\hline \multirow{2}{*}{ FAH SD } & $-2.1 \pm 1.02$ & $(-3.8$ to 0.4 .0$)$ & $0.95 \pm 0.03$ \\
\hline FAH/TH & $(-4.0$ to 0$)$ & $(0.87-0.99)$ & 0.66 \\
\hline
\end{tabular}

SD — standard deviation

Table 5. Differences between predicted vs. final adult height standard deviations (SDs) in patients with good control and patients with poor control $(n=54)$

\begin{tabular}{lccc}
\hline & $\begin{array}{c}\text { PAH SD } \\
\text { Median (IOR) }\end{array}$ & $\begin{array}{c}\text { FAH SD } \\
\text { Median (IQR) }\end{array}$ & p value \\
\hline Good control $(\mathrm{n}=8)$ & $-1.7(-2.5,-1.4)$ & $-1.5(-2.7,-1.35)$ & 0.37 \\
\hline Poor control $(\mathrm{n}=46)$ & $-1.4(-2.3,-0.75)$ & $-2.1(-2.6,-1.2)$ & $<0.001$ \\
\hline
\end{tabular}

$\mathrm{PAH}$ — predicted adult height; $\mathrm{FAH}$ — final adult height

$\mathrm{p}=0.02)$ and years between onset of puberty and menarche $(\mathrm{r}=0.36, \mathrm{p}=0.043)$ (Tab. 6).

\section{Discussion}

Patients with CAH due to 21-hydroxylase deficiency usually show FAH values below their genetically determined mid-parental target height [16].

In the current study the mean FAH attained in female patients with classic $\mathrm{CAH}$ was $150.36 \pm 7.23$ $\mathrm{cm}$, and in males it was $162.86 \pm 3.30 \mathrm{~cm}$. PAH in poorly controlled CAH patients using the B\&P method showed significant overestimation of final height but appropriately predicted the final adult height in the well-controlled CAH group. A negative correlation was found between final adult height SD and fludrocortisones dose.

Puberty relates more with skeletal than with chronological age [17], with onset in girls and boys occurring at approximately 11 and 13 years, respectively. For this reason, children with classic CAH may experience puberty slightly earlier than their healthy counterparts, 
Table 6. Correlations between final adult height (FAH), standard deviation (SD), and different clinical and biochemical parameters

\begin{tabular}{lcc}
\hline Correlations & $\mathbf{R}$ & p value \\
\hline FAH SD and BA at onset of puberty & -0.29 & 0.034 \\
\hline $\begin{array}{l}\text { FAH SD and percentage of FAH } \\
\text { at time of BA }\end{array}$ & -0.34 & 0.02 \\
\hline $\begin{array}{l}\text { FAH SD and hydrocortisone dose } \\
\text { [mg/m } / \text { day] }\end{array}$ & -0.11 & 0.43 \\
\hline FAH SD and dose of fludrocortisones & -0.41 & 0.005 \\
\hline FAH SD and weight & 0.32 & 0.02 \\
\hline FAH SDS and BMl & -0.04 & 0.77 \\
\hline $\begin{array}{l}\text { FAH SD and years between onset } \\
\text { of puberty and menarche in girls }\end{array}$ & 0.36 & 0.043 \\
\hline $\begin{array}{l}\text { Dose of hydrocortisone and } 17-0 \mathrm{H} \\
\text { progesterone }\end{array}$ & 0.304 & 0.027 \\
\hline
\end{tabular}

$\mathrm{BA}$ — bone age; $\mathrm{BMI}$ — body mass index

with the SV form being associated with the earliest puberty [18].

The median age at onset of puberty in our study was 12 years, with a wide range from 7 to 16 years reflecting the early puberty of SV children and the markedly delayed puberty of the uncontrolled females with hyperandrogenaemia and/or PCOS. Menarche occurred at a median age of 15 years. In the Klingensmith et al. study [19] 92\% of patients with menstrual delay had inadequate suppression of adrenal androgens due to poor compliance or insufficient doses of glucocorticoids (puberty is associated with increased cortisol clearance) [20], as occurred with the girls in our study. Onset of menarche was very much delayed and subsequently irregular in three of the female patients in our study group. In two (with 6- and 7-year delays), the reason was PCOS, which occurs in $30-40 \%$ of women with CAH [21].

In our study, however, there was no correlation between the age at onset of puberty (or age at menarche) with $\mathrm{FAH}$, and there was a negative correlation between the number of years between onset of puberty and menarche and FAH SD ( $p=0.043)$. This may be related to higher androgen levels in poorly controlled females, accelerating skeletal maturity while also delaying menarche.

The difference between bone age and chronological age in our patients showed a mean one-year advancement. Also, our patients had reached $70-99.8 \%$ of their final height (mean \pm SD: $90.56 \pm 6.9 \%$ ). Healthy girls on average have a total gain in height of $25 \mathrm{~cm}$ during the pubertal period compared to $28 \mathrm{~cm}$ in boys [9]. Height attainment in our patients through puberty was low, the assumption being that there was early skeletal maturation and closure of the epiphyses and/or decreased pubertal growth spurt $[22,23]$. Researchers studying the relationship between bone maturation and degree of $17 \mathrm{OHP}$ control found that BA was significantly delayed with tight control and significantly advanced by poor control [24]. Evidence derived from a meta-analysis of observational studies suggests that FAH in $\mathrm{CAH}$ is lower than both the population norm and target height [25]. This was not significantly associated with age at diagnosis, gender, type and dose of steroid, or age of onset of puberty.

Serum 17OHP is the traditional indicator of adequacy of glucocorticoid treatment in $\mathrm{CAH}$. Complete suppression of $17 \mathrm{OHP}$ levels is not a treatment goal but rather indicates overtreatment [7]. In our study, $17 \mathrm{OHP}$ levels ranged from extremely suppressed to very high values, indicating poor control at either of the two extremes. A disappointingly low percentage of our patients (14.8\%) had desired levels of $17 \mathrm{OHP}$. In this group, B\&P was able to accurately predict $\mathrm{FAH}$ at the onset of puberty. This was not the case in children with poor control, in whom B\&P tended to overestimate FAH by 0.7 SDS. Bone age at the onset of puberty had a negative correlation with FAH SD. Although FAH was significantly lower than target height in all patients and FAH was not significantly better in those with good control, it should be noted that a median of -1.5 SD suggests that optimal control at puberty may result in height within the normal range [26]. B\&P is usually intended for use in healthy children, but studies have employed this method to evaluate the effect of growth-promoting therapies in patients with $\mathrm{CAH}$ [27].

The B\&P method assists with height prediction by estimating the percentage of height already achieved, but it tends to overestimate FAH when compared to projected height in patients with advanced $B A$, and underestimate it with delayed BA [28].

The weights and BMIs in our study cases tended to be high. Our findings agree with those of Al Shaikh et al. [29], who concluded that children and adults with $\mathrm{CAH}$ are at an increased risk of developing obesity. Sarafoglou et al. showed that higher glucocorticoid dosage and advances in CA and BA were associated with an elevated BMI and obesity [30]. FAH correlated with body weight but not with BMI in our patients. This agrees with other studies in which obesity in CAH patients appeared to be correlated with reduced height potential [31].

Height outcome is related to the dose of corticosteroid, with some authors describing a negative correlation between hydrocortisone doses and FAH [32]. Although we noted that FAH in males on steroid doses $\leq 15 \mathrm{mg} / \mathrm{m}^{2} /$ day was significantly higher than in those receiving higher doses, we found no correlation between the actual dose of steroids and FAH, suggesting that growth is maintained within this cut-off dose. 
In addition to its mineralocorticoid action, its cortisone-like effect has resulted in the use of fludrocortisone as a steroid-sparing drug [5]. This has proven efficacious in many cases. Although only 23 of our patients had SW CAH, a total of 46 were receiving fludrocortisones as per the latest Endocrine Society clinical practice guidelines. These guidelines indicated that aldosterone deficiency is present in all forms of classic $\mathrm{CAH}$ although it is clinically apparent only in SW form [7]. Having said that, we noted that within the group of fludrocortisone-users $(82 \%)$ the actual dose correlated negatively with FAH ( $p=0.005)$. A recent study by Sellick et al. highlighted the importance of recognizing the glucocorticoid activity of fludrocortisone when calculating replacement regimens [33].

Although growth tends to be more severely affected in SW children $<2$ years of age because of salt loss and the need for higher doses of glucocorticoid [34], we found no difference in FAH between the SV and SW groups. This concurs with the findings of Manoli et al. [35]. However, males with SV CAH had significantly higher FAH SD than males with SW ( $p=0.01)$. This difference was not observed in females. This finding contradicts that of Nguyen et al., who recorded the poorest height prognosis in males with SV [31], and Pijenburg-Kleizen et al., who also described the worst FAH in children with SV CAH. They related this in part to late diagnosis and treatment and BA advancement. This male/female difference in height outcome in CAH patients where males fare more poorly has been described in other studies [34].

Treatment during puberty has to be individualised not only for growth but also because inadequate control has implications for future reproductive and sexual health. On the other hand, Cushing syndrome should be avoided [4].

\section{Limitations}

Because CAH is such a heterogenous disease in itself and because many adolescents are lost to follow-up, it was not possible to provide a more homogenous group of patients who fulfilled the inclusion criteria. Also, due to incomplete files, we were unable to calculate cumulative hydrocortisone doses received in the prepubertal years.

\section{Conclusions and recommendations}

$\mathrm{B} \& \mathrm{P}$ prediction can predict FAH in children with $\mathrm{CAH}$ at the onset of puberty if they are well-controlled, but it will overestimate FAH if not well controlled. The heights of females with $\mathrm{CAH}$, males with SW, or all those on high doses of hydrocortisone are lower than their genetic potentials. CAH is a heterogenous disease and the division of patients into SW and SV is arbitrary and simplistic. The true situation is that the disease is a continuum with many cases fitting somewhere between the two extremes. Management of the many problems of patients with $\mathrm{CAH}$ presents a unique challenge.

\section{Conflict of interest}

The authors declare no conflict of interest and that they had complete access to data and information relevant to the study.

\section{Funding}

The authors received no financial support or financial benefits from any party in connection with this work.

\section{Ethics approval}

The study was approved by the Research Ethics Committee of Cairo University and conducted in accordance with the Helsinki Declaration.

\section{Consent to participate}

Consent was obtained from all participants.

\section{Author's contribution}

The authors declare the integrity of the work.

All authors made a significant contribution to this manuscript, have seen and approved the final manuscript, and have agreed to its submission to the journal. N.A. shared in the study design, data collection and sorting for statistical analysis, drafting of the article, and final revision for publication. N.B. shared in the study design, critical revision of the article, interpretation of data, statistical analysis, drafting and writing of the manuscript, and final revision of the version to be published. A.K. shared in critical revision of the article, interpretation of data, statistical analysis, and final revision of the version to be published. A.A. shared in data collection, data entry, data analysis, and interpretation. L.F. shared in the design of the study, data collection, interpretation of data, drafting of the article, and final revision for publication.

\section{References}

1. Bonfig W, Odenwald B, Nennstiel-Ratzel U, et al. Blood pressure, fludrocortisone dose and plasma renin activity in children with classic congenital adrenal hyperplasia due to 21-hydroxylase deficiency followed from birth to 4 years of age. Clin Endocrinol (Oxf). 2014; 81(6): 871-875, doi: 10.1111/cen.12498, indexed in Pubmed: 24818525.

2. Tayel SM, Ismael H, Kandil H, et al. Congenital Adrenal Hyperplasia in Alexandria, Egypt: A High Prevalence Justifying the Need for a Community-based Newborn Screening Program. J Trop Pediatr. 2010 57(3): 232-234, doi: 10.1093/tropej/fmq064, indexed in Pubmed: 20615895.

3. Tayel SM, Ismael H, Kandil H, et al. Congenital adrenal hyperplasia in Alexandria, Egypt: a high prevalence justifying the need for a community-based newborn screening program. J Trop Pediatr. 2011; 57(3): 232-234, doi: 10.1093/tropej/fmq064, indexed in Pubmed: 20615895.

4. Merke DP, Poppas DP. Management of adolescents with congenital adrenal hyperplasia. Lancet Diabetes Endocrinol. 2013; 1(4): 341-352, doi: 10.1016/S2213-8587(13)70138-4, indexed in Pubmed: 24622419. 
5. Speiser PW, Azziz R, Baskin LS, et al. Endocrine Society. Congenital adrenal hyperplasia due to steroid 21-hydroxylase deficiency: an Endocrine Society clinical practice guideline. J Clin Endocrinol Metab. 2010; 95(9): 4133-4160, doi: 10.1210/jc.2009-2631, indexed in Pubmed: 20823466.

6. Seth A. Optimizing Stature in Congenital Adrenal Hyperplasia: Challenges and Solutions. Indian J Pediatr. 2019; 86(6): 489-491, doi: 10.1007/s12098-019-02961-0, indexed in Pubmed: 31030357.

7. Speiser PW, Arlt W, Auchus RJ, et al. Congenital Adrenal Hyperplasia Due to Steroid 21-Hydroxylase Deficiency: An Endocrine Society Clinical Practice Guideline. J Clin Endocrinol Metab. 2018; 103(11): 4043-4088, doi: 10.1210/jc.2018-01865, indexed in Pubmed: 30272171.

8. Tarim O. Accuracy of height prediction by Bayler Pinneau method. J Pediatr Endocrinol. 2016; 1: 1002.

9. Tanner JM, Whitehouse RH. Clinical longitudinal standards for height, weight, height velocity, weight velocity, and stages of puberty. Arch Dis Child. 1976; 51(3): 170-179, doi: 10.1136/adc.51.3.170, indexed in Pubmed: 952550.

10. Hargitai G, Sólyom J, Battelino T, et al. Growth Patterns and Final Height in Congenital Adrenal Hyperplasia due to Classical 21-Hydroxylase Deficiency. Horm Res Paed. 2001; 55(4): 161-171, doi: 10.1159/000049990, indexed in Pubmed: 11598369.

11. Aycan Z, Bas VN, Cetinkaya S, et al. Prevalence and long-term follow-up outcomes of testicular adrenal rest tumours in children and adolescent males with congenital adrenal hyperplasia. Clin Endocrinol (Oxf). 2013, 78(5): 667-672, doi: 10.1111/cen.12033, indexed in Pubmed: 23057653.

12. Hiernaux J, Tanner JM. Growth and physique: anthropometry. In Weiner JS, Lourie JA. ed. Human biology, a guide to field methods. Davis Company, Philadelphia 1969: 2-42.

13. Greulich WW, Pyle SI. Radiographic Atlas of Skeletal Development of the Hand and Wrist. 2nd ed. Stanford University Press, Stanford 1959

14. Bayley N, Pinneau SR. Tables for predicting adult height from skeleta age: revised for use with the Greulich-Pyle hand standards. J Pediatr. 1952; 40(4): 423-441, doi: 10.1016/s0022-3476(52)80205-7, indexed in Pubmed: 14918032

15. Merke DP. Approach to the adult with congenital adrenal hyperplasia due to 21-hydroxylase deficiency. J Clin Endocrinol Metab. 2008; 93(3): 653-660, doi: 10.1210/jc.2007-2417, indexed in Pubmed: 18326005.

16. Lin-Su K, Harbison MD, Lekarev O, et al. Final adult height in children with congenital adrenal hyperplasia treated with growth hormone. J Clin Endocrinol Metab. 2011; 96(6): 1710-1717, doi: 10.1210/jc.2010-2699, indexed in Pubmed: 21450983.

17. Martin DD, Wit JM, Hochberg Z, et al. The use of bone age in clinical practice - part 2. Horm Res Paediatr. 2011; 76(1): 10-16, doi: 10.1159/000329374 indexed in Pubmed: 21691055.

18. Trinh L, Nimkarn S, New MI, et al. Growth and pubertal characteristics in patients with congenital adrenal hyperplasia due to 21-hydroxylase deficiency. J Pediatr Endocrinol Metab. 2007; 20(8): 883-891, doi: 10.1515/jpem.2007.20.8.883, indexed in Pubmed: 17937061.

19. Klingensmith GJ, Garcia SC, Jones HW, et al. Glucocorticoid treatment of girls with congenital adrenal hyperplasia: effects on height, sexual maturation, and fertility. J Pediatr. 1977; 90(6): 996-1004, doi: 10.1016/s0022-3476(77)80581-7, indexed in Pubmed: 870661.

20. Charmandari E, Brook CGD, Hindmarsh PC. Classic congenital adrenal hyperplasia and puberty. Eur J Endocrinol. 2004; 151 Suppl 3: U77-U82, doi: 10.1530/eje.0.151u077, indexed in Pubmed: 15554890.

21. Papadakis G, Kandaraki EA, Tseniklidi E, et al. Polycystic Ovary Syndrome and NC-CAH: Distinct Characteristics and Common Findings. A Systematic Review. Front Endocrinol (Lausanne). 2019; 10: 388, doi: 10.3389/fendo.2019.00388, indexed in Pubmed: 31275245.

22. Lin YC, Lin CY, Chee SY, et al. Improved final predicted height with the injection of leuprolide in children with earlier puberty: A retrospective cohort study. PLoS One. 2017; 12(10): e0185080, doi: 10.1371/journal. pone.0185080, indexed in Pubmed: 28973010.

23. Bonfig W, Pozza SB, Schmidt H, et al. Hydrocortisone dosing during puberty in patients with classical congenital adrenal hyperplasia: an evidence-based recommendation. J Clin Endocrinol Metab. 2009; 94(10): 3882-3888, doi: 10.1210/jc.2009-0942, indexed in Pubmed: 19622620.

24. Girgis R, Winter JS. The effects of glucocorticoid replacement therapy on growth, bone mineral density, and bone turnover markers in children with congenital adrenal hyperplasia. J Clin Endocrinol Metab. 1997; 82(12): 3926-3929, doi: 10.1210/jcem.82.12.4320, indexed in Pubmed: 9398689.

25. Muthusamy K, Elamin MB, Smushkin G, et al. Clinical review: Adult height in patients with congenital adrenal hyperplasia: a systematic review and metaanalysis. J Clin Endocrinol Metab. 2010; 95(9): 4161-4172, doi: 10.1210/jc.2009-2616, indexed in Pubmed: 20823467.

26. Bozzola M, Meazza C. Growth velocity curves: What they are and how to use them. In: Preedy V. ed. Handbook of Growth and Growth Monitoring in Health and Disease. Springer, New York 2012: 2999-3011.

27. Lin-Su K, Harbison MD, Lekarev O, et al. Treatment with growth hormone and luteinizing hormone releasing hormone analog improves final adult height in children with congenital adrenal hyperplasia. J Clin Endocrinol Metab. 2005; 90(6): 3318-3325, doi: 10.1210/jc.2004-2128, indexed in Pubmed: 15797962.

28. Tarim O. Height predictions by Bayley-Pinneau method may misguide pediatric endocrinologists. Turkish J Pediatr . 2013; 55 (5): 485-492, indexed in Pubmed: 24382528.

29. Al Shaikh A, AlGhanmi Y, Awidah S, et al. Clinical Patterns and Linear Growth in Children with Congenital Adrenal Hyperplasia, an 11-Year Experience. Indian J Endocrinol Metab. 2019; 23(3): 298-306, doi: 10.4103/ijem.IJEM_99_19, indexed in Pubmed: 31641631.

30. Sarafoglou K, Forlenza GP, Yaw Addo O, et al. Obesity in children with congenital adrenal hyperplasia in the Minnesota cohort: importance of adjusting body mass index for height-age. Clin Endocrinol (Oxf). 2017; 86(5): 708-716, doi: 10.1111/cen.13313, indexed in Pubmed: 28199739.

31. Nguyen AnTt, Brown JJ, Warne GL. Growth in congenital adrenal hyperplasia. Indian J Pediatr. 2006; 73(1): 89-93, doi: 10.1007/BF02758268, indexed in Pubmed: 16444069.

32. Cordeiro GV, Silva IN, Goulart EM, et al. Final height in congenital adrenal hyperplasia: the dilemma of hypercortisolism vs. hyperandrogenism. Arq Bras Endocrinol Metabol. 2013; 57(2): 126-131, doi: 10.1590/s0004-27302013000200005, indexed in Pubmed: 23525290.

33. Sellick J, Aldridge S, Thomas M, et al. Growth of patients with congenital adrenal hyperplasia due to 21-hydroxylase in infancy, glucocorticoid requirement and the role of mineralocorticoid therapy. J Pediatr Endocrinol Metab. 2018; 31(9): 1019-1022, doi: 10.1515/jpem-2018-0260, indexed in Pubmed: 30173205.

34. Kim MS, Ryabets-Lienhard A, Geffner ME. Management of congenital adrenal hyperplasia in childhood. Curr Opin Endocrinol Diabetes Obes. 2012; 19(6): 483-488, doi: 10.1097/MED.0b013e32835a1a1b, indexed in Pubmed: 23037928.

35. Manoli I, Kanaka-Gantenbein Ch, Voutetakis A, et al. Early growth pubertal development, body mass index and final height of patients with congenital adrenal hyperplasia: factors influencing the outcome. Clin Endocrinol (Oxf). 2002; 57(5): 669-676, doi: 10.1046/j.1365-2265.200 2.01645.x, indexed in Pubmed: 12390343.

36. Pijnenburg-Kleizen KJ, Thomas CMG, Otten BJ, et al. Long-term follow-up of children with classic congenital adrenal hyperplasia: suggestions for age dependent treatment in childhood and puberty. J Pediatr Endocrinol Metab. 2019; 32(10): 1055-1063, doi: 10.1515/jpem-2019-0006, indexed in Pubmed: 31573958. 